\title{
Tratamento Térmico Solar da Água para Controle de Fitopatógenos*
}

\author{
Maria Aparecida S. Tanaka ${ }^{1}$, Margarida F. Ito ${ }^{1 * *}$, Carlos A. S. Braga ${ }^{2}$ (In Memorium) \\ \& Geraldo Armond ${ }^{2}$
}

${ }^{1}$ Centro de Pesquisa e Desenvolvimento de Fitossanidade, e-mail: matanaka@ @iac.br; ${ }^{2}$ Centro Avançado de Pesquisa
Tecnológica do Agronegócio de Engenharia e Automação, Instituto Agronômico de Campinas, Cx. Postal 28,
CEP 13001-970,Campinas, SP

(Aceito para publicação em 27/03/2003)

Autor para correspondência: Maria Aparecida de Souza Tanaka

TANAKA, M.A.S., ITO, M.F., BRAGA, C.A.S. \& ARMOND, G. Tratamento térmico solar da água para controle de fitopatógenos. Fitopatologia Brasileira 28:386-393. 2003.

\section{RESUMO}

Alguns microrganismos fitopatogênicos podem ser transportados pela água, que se constitui em importante e eficiente forma de disseminação. O controle de fitopatógenos pelo tratamento térmico da água infestada, utilizando a energia solar, constituiu o objetivo do trabalho. Quantificou-se a eficiência de um sistema automatizado de aquecimento solar desenvolvido para esta finalidade, baseado em processo misto de aquecimento da água em circuito fechado, com coletores planos e transmissão de calor por convecção natural e forçada. A automatização e a equalização da temperatura foram obtidas por termostatos localizados em diferentes pontos. Verificou-se boa eficiência do equipamento, trabalhando na temperatura de $60^{\circ} \mathrm{C}$, tanto em rendimento de água processada como na eliminação do inóculo de fitopatógenos de importância econômica, como Botrytis cinerea, Colletotrichum spp., Fusarium spp., Pythium spp., Verticillium dahliae e Rhizoctonia solani. À exceção de $F$. oxysporum f. sp. phaseoli, os patógenos testados não sobreviveram ao tratamento térmico a temperaturas acima de $55{ }^{\circ} \mathrm{C}$. A técnica mostrou-se promissora como uma opção na desinfestação da água para uso em irrigação de viveiros, casas de vegetação e diversas finalidades em pequenas ou médias propriedades agrícolas.

Palavras-chave adicionais: desinfestação térmica da água, tratamento solar da água, controle físico.

\section{ABSTRACT}

Solar heating of water for controlling phytopathogenic microorganisms

Some phytopathogenic microorganisms may be transmitted by water representing an efficient means way of inoculum dissemination. The objective of the work was to quantify the efficiency of thermal treatment by solar heating in the control of pathogens in contaminated water. The equipment developed for this purpose was composed of flat collectors and used both natural and forced convection to transfer heat to the circulating water. Thermostats, placed in different locataions, automatically equalized the temperature of the system. The equipment was verified to peform well at $60{ }^{\circ} \mathrm{C}$, in terms of water processed as well as in the eradication of economically important pathogens such as Botrytis cinerea, Colletotrichum spp., Fusarium spp., Pythium spp., Verticillium dahliae and Rhizoctonia solani. Except for F. oxysporum f. sp. phaseoli, the other pathogens were inactivated at temperatures above $55{ }^{\circ} \mathrm{C}$. The technique is a promising option to disinfest the water to be used in nurseries, greenhouses and in small or midsize agricultural exploitations.

\section{INTRODUÇÃO}

Alguns microrganismos fitopatogênicos podem ser transportados pela água, que se constitui em importante e eficiente forma de dispersão de patógenos em viveiros e culturas irrigadas (Hirst, 1965). Durante os períodos de irrigação por aspersão ou de chuva, além de a umidade favorecer a infecção e a dispersão do inóculo entre plantas, o impacto e o escorrimento das gotas arrastam os propágulos presentes no solo, infestando outras áreas. Nessas condições, a água excedente, que escorre após passar por culturas afetadas, principalmente em campos a montante, carrega inóculo que pode atingir

\footnotetext{
*Apoio financeiro: Fundação de Amparo à Pesquisa do Estado de São Paulo - FAPESP

**Bolsista do CNPq
}

os lagos e reservatórios utilizados para a irrigação. Quando a água é reciclada, o problema torna-se ainda mais grave, pelo acúmulo de estruturas reprodutivas dos patógenos (Hirst, 1965; Rotem \& Palti, 1969).

Embora a qualidade da água seja um dos fatores mais importantes na agricultura irrigada, existem poucos estudos sobre a contaminação dos recursos hídricos por microrganismos fitopatogênicos. A falta de monitoramento periódico da qualidade da água, decorrente da desinformação ou da falta de conscientização sobre o problema, aumenta o risco de introdução e disseminação de fitopatógenos em viveiros, cultivos hidropônicos e sistemas de produção protegidos ou a céu aberto (Carlos et al., 2001).

Em alguns países, como os Estados Unidos, a disseminação de patógenos pela água de irrigação está bem 
documentada, sendo espécies dos gêneros Fusarium, Phytophthora, Pythium e Rhizoctonia relatados como contaminantes de água de rios e outros mananciais, conforme comentam Freitas et al. (2001b). No Brasil, embora existam poucas informações a esse respeito, já se constatou que espécies de Fusarium, Pythium e Rhizoctonia, capazes de causar tombamento em plântulas de diversas espécies vegetais, podem ser encontrados na água de irrigação (Freitas et al. 2001b; Carlos et al. 2001). Em trabalhos conduzidos no Distrito Federal, Freitas et al. (2001a) atribuíram o aumento da incidência de tombamento de plântulas de alface (Lactuca sativa L.), cenoura (Daucus carota L.), couve-flor (Brassica oleraceae L. var. botrytis-cauliflora DC), ervilha (Pisum sativum L.), feijão (Phaseolus vulgaris L.), pepino (Cucumis sativus L.) e tomate (Lycopersicon esculentum Mill.) ao aumento da concentração de propágulos de fitopatógenos na água utilizada para irrigação, após passar por áreas com atividade agrícola.

Uma vez instalados no solo ou na cultura, o controle desses patógenos geralmente é difícil e demanda a utilização de produtos químicos que, além de onerarem o custo de produção, nem sempre são eficazes e podem levar à contaminação dos mananciais. Por essa razão, métodos preventivos, capazes de eliminar ou reduzir a quantidade de propágulos na água devem ser adotados.

Os métodos disponíveis e utilizados atualmente para a desinfestação de água podem ser químicos (como o cloro, por exemplo) ou não químicos (luz ultravioleta, microfiltragem, calor). O cloro pode ser eficiente contra grande número de patógenos, mas nas dosagens efetivas, geralmente é fitotóxico. Defensivos agrícolas não são recomendados para tal fim, pois poderiam trazer problemas para o ser humano e o ambiente (Jarvis, 1993; Carmelo, 1996).

O tratamento da água pelo calor baseia-se no efeito de temperaturas elevadas sobre a atividade celular dos patógenos. A maioria dos microrganismos fitopatogênicos apresenta ponto térmico letal a temperaturas na faixa de 45 a $60{ }^{\circ} \mathrm{C}$. O mecanismo mais provável responsável pela morte em altas temperaturas é resultante da desnaturação de proteínas e enzimas, importantes para o metabolismo celular (Cochrane, 1958; Deverall, 1965). O tratamento térmico da água com a utilização da energia solar constitui uma opção promissora e tecnicamente viável de controle, a exemplo da solarização e do coletor solar plano, técnicas empregadas com sucesso para o controle de patógenos do solo (Katan et al., 1970; Pulman, 1981; Armond et al, 1990). O uso da energia solar para as finalidades mencionadas é interessante por ser fonte renovável e não poluidora e se constituir em uma alternativa ao alto custo da energia elétrica. Além disso, trata-se de um insumo gratuito e abundante no Brasil, que recebe um valor médio de incidência de energia solar direta da ordem de $200 \mathrm{~W} / \mathrm{m}^{2}$, junto com uma insolação média anual ao redor de 2.500 a 3.000 h/ano (Bezerra, 1979, Palz, 1981).

Neste trabalho objetivou-se verificar a eficiência de um equipamento solar para tratamento térmico da água, visando ao controle de fitopatógenos.

\section{MATERIAL EMÉTODOS}

\section{Determinação do binômio tempo-temperatura letal para alguns fitopatógenos}

Foram utilizados os seguintes fitopatógenos, comumente associados a várias culturas de importância econômica: Colletotrichum acutatum Simmonds, C. fragariae Brooks, Fusarium spp., Pythium sp. e Phytophthora cactorum (Leb. \& Cohn) Schroet., isolados de morangueiro (Fragaria $\mathrm{x}$ ananassa Duch.), C. lindemuthianum (Sacc. \& Magn.) Br. \& Cav., de feijoeiro, Diaporthe phaseolorum (Cke. \& Ell.) Sacc.f. sp. meridionalis Morgan-Jones, de soja [Glycine Max (L.) Merril], Fusarium subglutinans Nelson et al.) f. sp. ananas, de abacaxi [Ananas comosus (L.) Merr.], F. solani (Mart.) Sacc. f. sp. phaseoli (Burk.) Snyder \& Hansen, de feijoeiro, Pythium sp., de alface, Rhizoctonia solani Kühn, de feijão vagem e morangueiro, Sclerotium rolfsii Sacc., de mamoeiro (Carica papaya L.) e pimentão (Capsicum annuum L.), Verticillium dahliae Kleb., de berinjela (Solanum melognena L.) e tomateiro.

Foram preparadas suspensões na concentração de $10^{6}$ esporos/ml para os patógenos esporulantes e para $R$. solani $e$ $S$. rolfsii foram utilizadas suspensões de micélio e micélio mais esclerócios, respectivamente. Essas suspensões foram colocadas, assepticamente, em tubos de ensaio esterilizados e submetidas às temperaturas de $35,40,45,50,55$ e $60^{\circ} \mathrm{C}$, em banho-maria, durante 10,20 e 30 min em cada uma delas. Em seguida, alíquotas das suspensões tratadas termicamente foram plaqueadas em meio de cultura BDA (batata $200 \mathrm{~g}$, dextrose $20 \mathrm{~g}$, agar 17-20 g e água destilada $1.000 \mathrm{ml}$ ) e submetidas à temperatura de $26{ }^{\circ} \mathrm{C}$ durante sete dias. $\mathrm{O}$ delineamento experimental foi inteiramente ao acaso, com quatro repetições constituídas por dez placas. Como tratamentos testemunhas, alíquotas de suspensões de cada patógeno, sem serem submetidas ao tratamento térmico, foram plaqueadas em BDA.

O desenvolvimento das colônias na superfície do meio foi quantificado por escala visual considerando-se: a) crescimento intenso: desenvolvimento semelhante à testemunha sem tratamento térmico, com formação de colônias densa e uniformemente distribuídas; b) crescimento moderado: colônias com massa micelial menos compacta e/ou menor número de colônias por placa; c) crescimento fraco: redução do número de colônias formadas, que também apresentaram densidade micelial reduzida; d) traços: presença de pequenas colônias, esparsas e em número muito reduzido.

\section{Descrição do equipamento}

$\mathrm{O}$ equipamento foi montado com coletores solares planos e o aquecimento da água obtido empregando-se dois princípios integrados de transmissão de calor, um por convecção natural e o outro por convecção forçada, em circuito térmico fechado. A energia térmica gerada nos coletores é transferida à massa de água em circulação, até ser atingida a temperatura programada. Monitores termostáticos diferenciais, interligados à parte hidráulica e aos demais componentes, automatizaram o 
sistema e equalizaram a temperatura em toda a massa de água, de acordo com o esquema apresentado (Figura 1).

A comprovação da eficiência e do rendimento do equipamento na produção de água tratada termicamente foi feita por testes normativos de avaliação tecnológica do sistema, usando-se o método de ensaio IPT (1981), relatados por Braga et al. (2001). Este método se baseou em testes conduzidos em função das temperaturas operacionais programadas de 50, 55 e $60^{\circ} \mathrm{C}$, faixa referencial de temperatura que, durante o tempo de $10 \mathrm{~min}$, é letal para a maioria dos microrganismos fitopatogênicos (Cochrane, 1958; Deverall, 1965).

\section{Eficiência do equipamento na desinfestação da água}

Os seguintes patógenos e suas respectivas plantas de origem, pertencentes a micoteca da Fitopatologia do IAC, foram testados quanto à sobrevivência, após o tratamento térmico no equipamento desenvolvido: Botrytis cinerea Pers. ex Fr. (morangueiro), C. acutatum (morangueiro), C. fragariae (morangueiro), Diaporthe phaseolorum f. sp. meridionalis (soja), Fusarium oxysporum Schlecht. f. sp. phaseoli Kendrick \& Snyder (feijoeiro), Fusarium sp. (morangueiro), P. cactorum (morangueiro), Pythium sp. (alface), Pythium sp. (morangueiro), $R$. solani (feijão vagem), $R$. solani (morangueiro), V. dahliae (berinjela), V. dahliae [quiabeiro (Albemoschus esculentus (L.) Moench.) ] e Xanthomonas axonopodis pv. phaseoli (feijoeiro).

Os inóculos foram preparados a partir de culturas puras desenvolvidas em meio de BDA, contido em placas de Petri de $9 \mathrm{~cm}$ do diâmetro, mantidas em estufa incubadora na temperatura de 26 a $28^{\circ} \mathrm{C}$ durante sete dias, no escuro. Após esse período, foi adicionada água destilada em cada placa e procedeu-se a raspagem cuidadosa da superfície das colônias com uma lâmina de microscopia esterilizada. Em seguida, a suspensão de inóculo obtida foi filtrada em camada dupla de gaze, determinando-se sua concentração com a câmara de Neubauer. No caso de fungos não esporulantes, como $R$. solani, obteve-se apenas suspensão micelial e, para a bactéria $X$. axonopodis pv. phaseoli, utilizou-se a suspensão de células.

O inóculo de cada patógeno foi colocado no reservatório de alimentação (Figura 1), completando-se o volume com água, até se obter $250 \mathrm{ml}$ à concentração de $10^{5}$ esporos $/ \mathrm{ml}$, no caso de fungos esporulantes. Do reservatório de alimentação, a água contendo o inóculo foi introduzida no equipamento, sendo aquecida nas temperaturas e tempos programados para os testes. Coletaram-se amostras nas seguintes fases: antes do aquecimento, para constituir a testemunha, e após $10 \mathrm{~min}$ de exposição nas faixas de temperatura de $40-45^{\circ} \mathrm{C}, 45-50{ }^{\circ} \mathrm{C}$, $50-55^{\circ} \mathrm{C}, 55-60^{\circ} \mathrm{C}, 60-65^{\circ} \mathrm{Ce} 65-70^{\circ} \mathrm{C}$.

A sobrevivência dos patógenos foi avaliada em ensaios de laboratório e/ou casa de vegetação, com oito tratamentos, representados pelas seis faixas de temperatura, a testemunha constituída da amostra retirada antes do aquecimento e uma testemunha absoluta (água destilada esterilizada).

\section{Sobrevivência dos patógenosin vitro}

De cada faixa de temperatura retiram-se amostras, em alíquotas de $50 \mathrm{ml}$, das quais utilizou-se $1 \mathrm{ml}$, que foi unifor- memente distribuído na superfície de meios de cultura BDA e AA (agar-água), contidos em placas de Petri. Para cada tratamento foram utilizadas cinco placas de cada meio de cultura. A incubação foi realizada em estufa incubadora, a 26$28^{\circ} \mathrm{C}$, durante sete a dez dias, no escuro.

A avaliação consistiu em quantificar a intensidade de crescimento das colônias desenvolvidas, adotando-se a escala descrita.

\section{Sobrevivência dos patógenosin vivo}

Estes testes foram conduzidos em delineamento experimental inteiramente ao acaso, com quatro repetições, em casa de vegetação, exceto para $B$. cinerea, $C$. acutatum e para a bactéria $X$. axonopodis pv. phaseoli, que foram avaliados em laboratório.

a) Botrytis cinerea. Foram utilizados frutos destacados de morango cultivar IAC Campinas, de tamanho e coloração uniformes, em início de amadurecimento (cerca de $70 \%$ da superfície apresentando coloração rosada). Após desinfestação superficial em hipoclorito de sódio a $1 \%$ durante $3 \mathrm{~min}$, os frutos foram lavados em água destilada, secos ao ar sobre papel toalha por $2 \mathrm{~h}$ e colocados no interior de caixas plásticas de $4 \times 11 \times 11 \mathrm{~cm}$, transparentes e com tampa (Gerbox), forradas com papel mata-borrão umedecido com água destilada. Em cada caixa foram colocados quatro frutos, eqüidistantes entre si, constituindo uma repetição.

A inoculação consistiu na pulverização da suspensão de conídios sobre os frutos. A avaliação foi efetuada cinco dias após, considerando-se viável o inóculo dos tratamentos em que houve crescimento do fungo sobre os frutos, com sintomas característicos da doença (mofo cinzento). Avaliouse também, visualmente, a porcentagem da superfície do fruto coberta pelo fungo.

b) Colletotrichum acutatum. A comprovação da sobrevivência foi feita inoculando-se frutos destacados de morango cultivar IAC Campinas. Os frutos foram desinfestados superficialmente, secos ao ar e acondicionados em Gerbox, em procedimento semelhante ao descrito para $B$. cinerea. Cada repetição foi representada por uma caixa com quatro frutos.

A inoculação consistiu na deposição de uma gota do inóculo sobre ferimentos efetuados nos frutos, com o auxílio de seringa hipodérmica. A incubação foi realizada em ambiente de laboratório durante sete dias e considerou-se viável o inóculo dos tratamentos em que se verificou a formação de lesões de antracnose nos locais da inoculação. A severidade dos sintomas foi avaliada medindo-se o tamanho médio das lesões, tomando-se dois diâmetros perpendiculares entre si.

c) Colletotrichum fragariae. Foram utilizadas plantas de morango cultivar AGF-80, mantidas em vasos com capacidade de 1,5 1, contendo mistura constituída de duas partes de solo e uma parte de areia, esterilizada em autoclave. Foi considerada como repetição um vaso com duas plantas. O método de inoculação foi semelhante ao utilizado por Tanaka et al. (1999), 
colocando-se uma gota de inóculo sobre ferimento efetuado no terço inferior de quatro pecíolos da parte mediana da planta. As plantas inoculadas foram mantidas $48 \mathrm{~h}$ em câmara úmida. As avaliações foram realizadas aos 20 dias após, verificandose a presença de lesões marrom-escuras, alongadas e deprimidas (características de antracnose) nos locais de inoculação. A severidade foi avaliada em função do diâmetro médio das lesões.

d) Fusarium oxysporum f. sp.phaseoli. As raízes de plântulas de feijoeiro cultivar IPA-6, com cerca de sete dias de idade, produzidas em bandejas com areia esterilizada por autoclavagem, foram lavadas e suas extremidades cortadas com tesoura. Logo em seguida, as raízes foram mergulhadas no inóculo (método de "dipping") por $10 \mathrm{~min}$ (Costa et al., 1989). As plântulas inoculadas foram transplantadas para vasos com capacidade de 1,5 1, contendo uma mistura esterilizada de solo e areia $(2 \mathrm{v}: 1 \mathrm{v})$. Cada repetição foi representada por um vaso com quatro plantas

A avaliação foi efetuada 30 dias após a inoculação, utilizando-se a escala de notas para severidade de sintomas, de acordo com Nascimento (1995).

e) Verticillium dahliae. Foram utilizadas plantas de quiabo (Abelmoschus esculentus L), com aproximadamente $15 \mathrm{~cm}$ de altura, cultivadas em vasos, sendo considerada cada repetição um vaso com duas plantas.

A inoculação consistiu na imersão (“dipping”), por 10 min, das raízes das plantas, previamente arrancadas, lavadas e cortadas nas extremidades, de modo semelhante ao utilizado para $F$. oxysporum f. sp. phaseoli. Decorridos 45 dias da inoculação, as plantas foram avaliadas quanto a sintomas de murcha e escurecimento de vasos, indicativos da infecção pelo patógeno, utilizando-se escala de notas de 0 a 4 , crescente para severidade de sintomas.

f) Xanthomonas axonopodis pv. phaseoli. Foram utilizadas folhas de feijoeiro cultivar IAC-Carioca Aruã, destacadas e de tamanho uniforme colocadas sobre papel mata-borrão umedecido com água destilada esterilizada, no interior de caixas Gerbox. A inoculação foi efetuada pela técnica de agulhas múltiplas (Valarini, 1990), pressionadas sobre os folíolos, cuja superfície inferior foi mantida em contato com uma esponja previamente mergulhada no inóculo. As folhas inoculadas permaneceram em ambiente de laboratório durante sete dias, quando se avaliou a presença de lesões típicas do crestamento bacteriano comum.

\section{RESULTADOSE DISCUSSÃO}

A maioria dos patógenos testados não sobreviveu ao tratamento térmico a temperaturas acima de $50^{\circ} \mathrm{C}$ (Tabela 1$)$, corroborando com relatados de literatura, como Bollen (1985) e Silva et al. (1996). Para as espécies de Pythium, Colletotrichum e $P$. cactorum a temperatura de $45^{\circ} \mathrm{C}$ por 30 min foi suficiente para inativar o inóculo. Colletotrichum

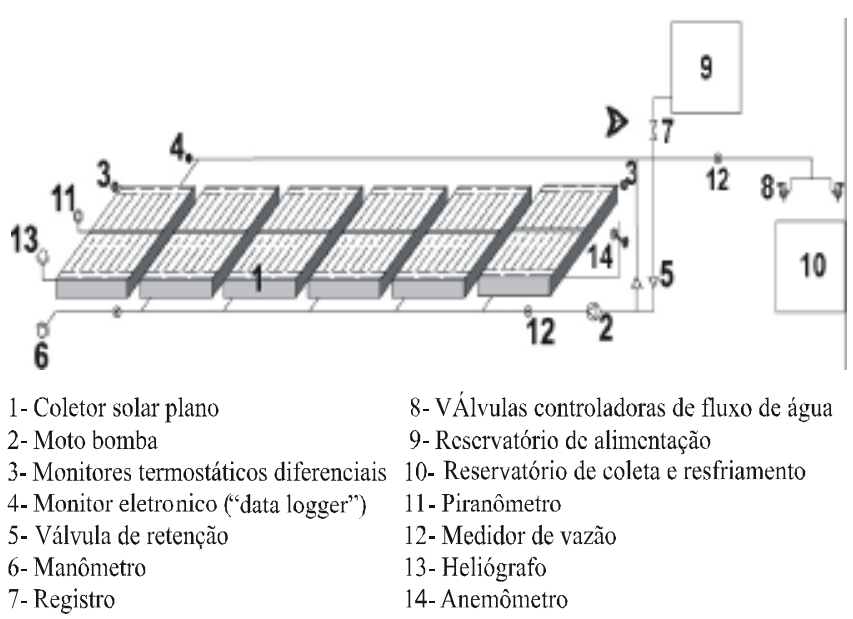

FIG. 1 - Esquema técnico da montagem do equipamento solar.

acutatum, C. lindemuthianum e Pythium sp. isolado de alface, foram mais sensíveis ao efeito da temperatura e não sobreviveram ao tratamento térmico acima de $40^{\circ} \mathrm{C}$ por $30 \mathrm{~min}$ (Tabela 1).

No tratamento a $50{ }^{\circ} \mathrm{C}$ verificou-se que $R$. solani e $S$. rolfsii sobreviveram até 20 min de exposição, mas perderam a viabilidade quando o tempo atingiu $30 \mathrm{~min}$. Para $V$. dahliae, a viabilidade foi mantida, ainda que em traços, pela exposição até $50{ }^{\circ} \mathrm{C}$ durante $10 \mathrm{~min}$; aos 20 min o inóculo foi inativado.

Dentre os fungos do gênero Fusarium avaliados, $F$. subglutinans permaneceu viável após tratamento a $55^{\circ} \mathrm{C}$ por 30 min, enquanto, para as demais espécies, ainda foi observado crescimento pela exposição a $60^{\circ} \mathrm{C}$ durante 10 min (Tabela 1).

Esses resultados, aliados aos dados disponíveis na literatura consultada, permitiram o embasamento para se estabelecer as faixas de temperatura para o aquecimento da água, a serem atingidas pelo equipamento.

Um aspecto importante do sistema é a equalização da temperatura da água no interior dos coletores solares, resultante da transmissão de calor por convecção forçada, que impede a formação de gradientes em pontos inferiores da massa de água (Braga et al., 2001). Esses gradientes, comuns nos sistemas convencionais de aquecimento solar da água, são causados pelas correntes de convecção natural e criam zonas menos quentes nas seções inferiores dos coletores (Duffie, 1974; Lunde, 1980). Ressalta-se que, para a finalidade de desinfestação térmica da água, a que se propôs o trabalho, a utilização desses sistemas convencionais, já disponíveis para uso doméstico e outros fins, não seria eficiente, pois sem a equalização da temperatura essas zonas menos quentes poderiam permitir a sobrevivência de propágulos de fitopatógenos. Durante os testes confirmou-se essa uniformidade por meio do monitor eletrônico (“data logger").

O rendimento médio diário de água processada, em $\mathrm{Kg}$ / $\mathrm{m}^{2}$ dia (quantidade por metro quadrado de placa solar), exceto nos meses de julho e outubro (Figura 2), foi superior à média de $50 \mathrm{Kg} / \mathrm{m}^{2}$ dia dos sistemas convencionais similares atualmente usados no Brasil, principalmente para fins domésticos (ABNT, 1981; Braga et al., 2001). 


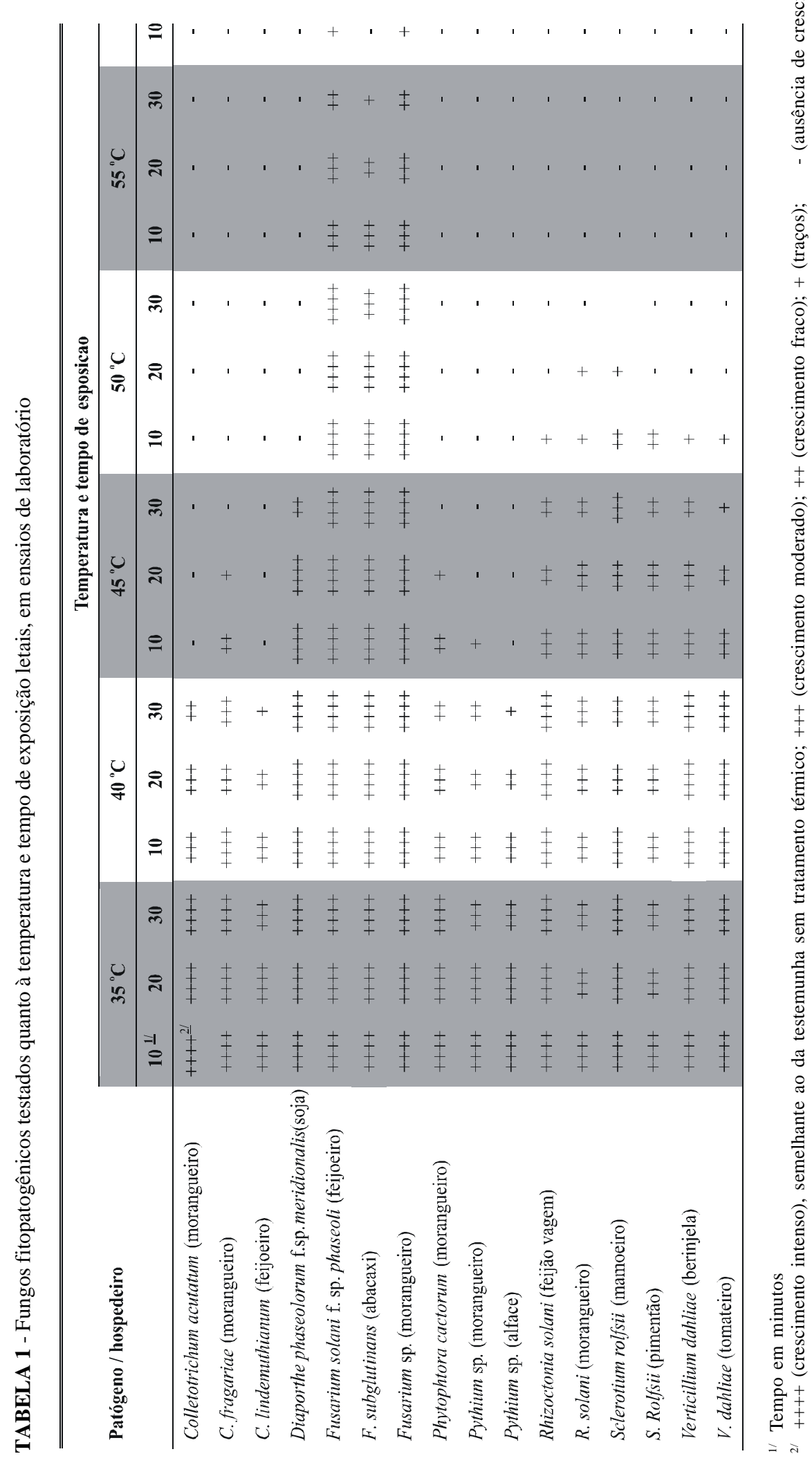


Os dados obtidos in vitro e apresentados na Tabela 2 confirmaram os resultados da Tabela 1, verificando-se que a sobrevivência da maioria dos patógenos avaliados não ultrapassou a exposição à faixa de temperatura de $45-50^{\circ} \mathrm{C}$.

Fusarium oxysporum f. sp. phaseoli e Fusarium sp., originários de feijoeiro e morangueiro, respectivamente, mantiveram-se viáveis até $55-60{ }^{\circ} \mathrm{C}$, enquanto $V$. dahliae (isolado de quiabeiro) e $X$. axonopodis pv. phaseoli (feijoeiro) sobreviveram ao tratamento a $50-55^{\circ} \mathrm{C}$.

A viabilidade dos isolados de C. acutatume P. cactorum provenientes de morangueiro, bem como de Pythium sp. de alface, foi mantida até $45-50{ }^{\circ} \mathrm{C}$, semelhante ao verificado na primeira etapa do trabalho (Tabela 1). Para $C$. fragariae, no entanto, ainda se detectaram traços de crescimento a $45-50{ }^{\circ} \mathrm{C}$, o que indica ser este patógeno mais resistente ao calor do que C. acutatum.

Diaporthe phaseolorum f. sp. meridionalis e os dois isolados de $R$. solani e $V$. dahliae mantiveram-se viáveis após tratamento a $45-50{ }^{\circ} \mathrm{C}$ (Tabela 2 ), registrando-se nesta temperatura traços de crescimento, do mesmo modo que nos testes realizados in vitro, na primeira etapa do trabalho (Tabela 1).

Em testes in vivo (Tabela 3 ), à exceção de $F$. oxysporum f. sp. phaseoli, os demais patógenos não sobreviveram ao tratamento térmico a temperaturas acima de $50-55^{\circ} \mathrm{C}$, semelhante ao observado nos ensaios in vitro (Tabela 2). Embora o referido fungo tenha sobrevivido a temperaturas de até $60^{\circ} \mathrm{C}$ nos testes in vitro, no ensaio in vivo, a viabilidade foi mantida até $55^{\circ} \mathrm{C}$. Do mesmo modo, os testes in vitro indicaram que a sobrevivência de $V$. dahliae (isolado de quiabeiro) e de $X$. axonopodis pv. phaseoli foi preservada até $50-55^{\circ} \mathrm{C}$ (Tabela 2 ), sendo que, nos testes in vivo, houve perda da viabilidade nesta faixa de temperatura (Tabela 3 ). Observa-se que houve redução da intensidade dos sintomas de mofo cinzento $(B$.

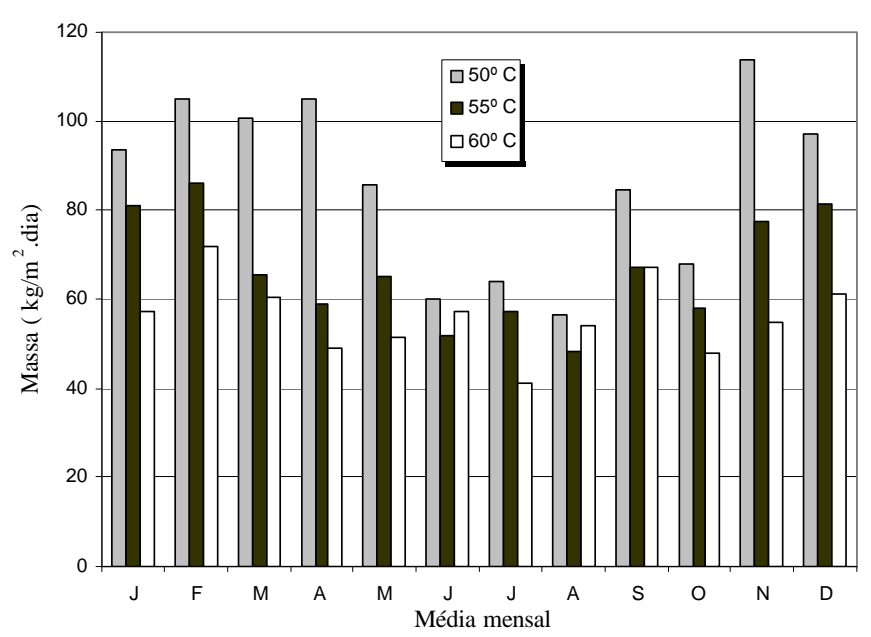

FIG. 2 - Produção média diária (7 h) de água processada, por unidade de área do coletor solar, nas três temperaturas programadas.

cinerea), de antracnose (C.acutatum e $C$. fragariae) e das murchas causadas por $F$. oxysporum f. sp. phaseoli e por $V$. dahliae (escala de notas de 0 a 4), com o aumento da temperatura de exposição do inóculo (Tabela 4).

Embora mais estudos sejam necessários para confirmação da viabilidade técnica do equipamento, os resultados obtidos indicam que a sua utilização é promissora para a desinfestação da água para ser empregada na irrigação e em outras finalidades agrícolas. Verificou-se boa eficiência, trabalhando na temperatura de $60^{\circ} \mathrm{C}$, na eliminação do inóculo de fitopatógenos de importância econômica. Dentre eles, espécies dos gêneros Fusarium, Phytophthora, Pythium e Rhizoctonia, responsáveis por tombamento em diversas plantas, já foram isoladas de reservatórios utilizados para

TABELA 2 - Sobrevivência dos patógenos submetidos ao tratamento térmico no equipamento desenvolvido, em diferentes faixas de temperatura, em testes realizados in vitro

\begin{tabular}{|c|c|c|c|c|c|c|c|}
\hline \multirow{2}{*}{ Patógeno / hospedeiro } & \multicolumn{7}{|c|}{ Tratamentos } \\
\hline & Test. $1 \stackrel{1 /}{1}$ & Test. $2 \underline{2 l}$ & $40-45^{\circ} \mathrm{C}$ & $45-50{ }^{\circ} \mathrm{C}$ & $50-55^{\circ} \mathrm{C}$ & $55-60{ }^{\circ} \mathrm{C}$ & $60-65^{\circ} \mathrm{C}$ \\
\hline Botrytis cinerea (morangueiro) & - & ++++ & ++ & - & - & - & - \\
\hline Colletotrichum acutatum (morangueiro) & - & ++++ & ++ & - & - & - & - \\
\hline C. fragariae (morangueiro) & - & ++++ & +++ & + & - & - & - \\
\hline Diaporthe phaseolorum f. sp. meridionalis (soja) & - & ++++ & +++ & + & - & - & - \\
\hline Fusarium oxysporum f. sp. phaseoli (feijoeiro) & - & ++++ & ++++ & +++ & ++ & + & - \\
\hline Fusarium sp. (morangueiro) & - & ++++ & +++ & +++ & ++ & + & - \\
\hline Phytophthora cactorum (morangueiro) & - & ++++ & + & - & - & - & - \\
\hline Pythium sp. (alface) & - & ++++ & + & - & - & - & - \\
\hline Pythium sp. (morangueiro) & - & ++++ & + & - & - & - & - \\
\hline Rhizoctonia solani (FeijãoVagem) & - & ++++ & ++ & + & - & - & - \\
\hline R. solani (morangueiro) & - & ++++ & ++ & + & - & - & - \\
\hline Verticillium dahliae (berinjela) & - & ++++ & +++ & + & - & - & - \\
\hline V. dahliae (quiabeiro) & - & ++++ & +++ & + & + & - & - \\
\hline Xanthomonas axonopodis pv. phaseoli (feijoeiro) & - & ++++ & +++ & + & + & - & - \\
\hline
\end{tabular}

1 1 Test. 1 = Testemunha absoluta (água destilada esterilizada)

2/ Test. 2 = Inóculo sem tratamento térmico

$\underline{31}++++$ (crescimento intenso, semelhante ao da testemunha $2 ;+++($ crescimento moderado $) ;++($ crescimento fraco $) ;+$ (traços $) ;-($ ausência de crescimento). 
M.A.S. Tanaka et al.

TABELA 3 - Incidência de sintomas de diferentes patógenos em testes in vivo, com inóculo submetido ao tratamento térmico

\begin{tabular}{|c|c|c|c|c|c|c|}
\hline \multirow{2}{*}{ Patógeno } & \multicolumn{6}{|c|}{ Tratamentos } \\
\hline & Test. $1^{1 /}$ & Test. $2^{2 /}$ & $40-45^{\circ} \mathrm{C}$ & $45-50$ "C & $50-55^{\circ} \mathrm{C}$ & $55-60{ }^{\circ} \mathrm{C}$ \\
\hline & \multicolumn{6}{|c|}{$\begin{array}{l} \\
\end{array}$} \\
\hline Botrytis cinerea & 0 & $100^{\underline{3} /}$ & 79 & 0 & 0 & 0 \\
\hline Colletotrichum acutatum & 0 & $100 \stackrel{4}{\prime}$ & 56 & 0 & 0 & 0 \\
\hline C. fragariae & 0 & $100 \stackrel{5}{\prime}$ & 68 & 12 & 0 & 0 \\
\hline Fusarium oxysporum f.sp. phaseoli & 0 & $96^{6 /}$ & 75 & 37 & 16 & 0 \\
\hline Verticillium dahliae & 0 & $100^{6 /}$ & 60 & 18 & 0 & 0 \\
\hline
\end{tabular}

$\underline{1}$ Test. 1 = Testemunha absoluta (água destilada esterilizada)

2/ Test. 2 = Inóculo sem tratamento térmico

3/ Incidência de mofo cinzento em morango

4/ Incidência de antracnose em morango

- Incidência de lesões > $5 \mathrm{~mm}$ em pecíolos de morangueiro, 15 dias após a inoculação

6/ Incidência de murcha e/ou escurecimento de vasos de feijoeiro

${ }^{\text {7l}}$ Incidência de crestamento bacteriano comum em folhas de feijoeiro

TABELA 4 - Intensidade de sintomas provocados por Botrytis cinerea, Colletotrichum acutatum, C. fragariae, Fusarium oxysporum f. sp. phaseoli e Verticillium dahliae em frutos de morango (Fragaria x ananassa), em feijoeiro (Phaseolus vulgaris) e em quiabeiro (Albemoschus esculentus), respectivamente, em função do tratamento térmico do inóculo

\begin{tabular}{|c|c|c|c|c|c|c|}
\hline \multirow{2}{*}{ Patógeno } & \multicolumn{6}{|c|}{ Tratamentos } \\
\hline & Test. $1^{1 /}$ & Test. $2 \underline{2 /}$ & $40-45^{\circ} \mathrm{C}$ & $45-50{ }^{\circ} \mathrm{C}$ & $50-55^{\circ} \mathrm{C}$ & $55-60{ }^{\circ} \mathrm{C}$ \\
\hline Botrytis cinerea & 0,0 & $90,0^{3 /}$ & 72,0 & 0,0 & 0,0 & 0,0 \\
\hline Colletotrichum acutatum & 0,0 & $12,8^{4}$ & 7,3 & 0,0 & 0,0 & 0,0 \\
\hline C. fragariae & 0,0 & $>20,0^{-\frac{1}{\prime}}$ & 16,1 & 9,3 & 0,0 & 0,0 \\
\hline Fusarium oxysporum f.sp. phaseoli & 0,0 & $3,8 \underline{6}$ & 3,1 & 2,2 & 1,0 & 0,0 \\
\hline Verticillium dahliae & 0,0 & $3,5^{7 /}$ & 2,6 & 0,0 & 0,0 & 0,0 \\
\hline
\end{tabular}

1/ Test. 1 = Testemunha absoluta (água destilada esterilizada)

2/ Test. 2 = Inóculo sem tratamento térmico

3. Porcentagem da superfície do fruto de morango coberta pelo fungo

4/Diâmetro médio da lesão em fruto de morango, em $\mathrm{mm}$

5'Diâmetro médio da lesão em pecíolos de morangueiro, em mm, aos 20 dias após a inoculação

6/ Escala de notas de 0 a 4

7/ Escala de notas de 0 a 4

irrigação (Freitas et al., 2001b, Carlos et al., 2001).

Uma outra aplicação desta técnica de desinfestação térmica da água é na hidroponia. Nesta modalidade de cultivo, as doenças são um sério problema, sendo, as vezes, limitantes. Nesses sistemas observa-se com freqüência a ocorrência de doenças que são extremamente favorecidas, devido à uniformidade genética e proximidade das plantas, facilidade de disseminação rápida e uniforme dos propágulos de patógenos pela própria solução nutritiva e pela temperatura e umidade relativa propícias para a infecção (Stangellini \& Rasmussen, 1994). Sendo a água, comprovadamente, um dos mecanismos mais eficientes de introdução dos patógenos na hidroponia (Jarvis, 1993), o seu tratamento térmico antes de compor a solução seria uma opção de controle preventivo dos principais microrganismos potencialmente patogênicos.

\section{REFERÊNCIAS BIBLIOGRÁFICAS}

ABNT - Associação Brasileira de Normas Técnicas. Projeto de Norma - Método de ensaio de coletores solares planos para líquidos determinação do rendimento térmico. Minuta 2. 1981.

ARMOND, G., BRAGA, C.A.S., BETTIOL, W. \& GHINI, R. Coletor solar plano para tratamento térmico do solo. O Agronômico 42:185189. 1990.

BEZERRA, A.M. Aplicações práticas da energia solar. João Pessoa. Editora Universitária - UFPb. 1979.

BOLLEN, G.J. Lethal temperatures of soil fungi. In: Parker, C.A., Rovira, A.D., Moore, K.J., Wong, P.T.W. \& Kollmorgen, J.F. (Eds.) Ecology and management of soil borne plant pathogens. St. Paul. American Phytopathological Society. 1985. pp.191-193.

BRAGA, C.A., ARMOND, G., TANAKA, M.A.S., ITO, M.F., MESQUITA, C.M., MAZIERO, J.V.G., BERNARDI, J.A. \& PECHE FILHO, A. Sistema automatizado de aquecimento solar para controle de fitopatógenos da água de irrigação. Revista Brasileira de Engenharia Agrícola e Ambiental 5:327-333. 2001.

CARLOS, R.M.E., NASSER, L.C.B., LAMY, A.C.M. \& FREITAS, M.A. Influência da qualidade de sementes e da água de irrigação no sistema de produção de mudas de espécies floríferas no Distrito Federal. Anais, $19^{\circ}$ Encontro Nacional de Arborização Urbana, Brasília, DF. CD Room. 2001.

CARMELO, Q. A qualidade da água. Parte III. Hidropomanias \& Cia 5:1.1996.

COCHRANE, V.W. The physiology of fungi. New York. John Wiley \& Sons Inc. 1958. 
COSTA, A.F., COELHO NETTO, R.A. \& MIRANDA, P. Método de inoculação de Fusarium oxysporum f. sp. phaseoli em feijão visando seleção de linhagens resistentes. Fitopatologia Brasileira 14:135. 1989.

DEVERALL, B.J. The physical environment for fungal growth. In: Ainsworth, G.C. \& Sussman, A .S. (Eds.) The fungi - An advanced treatise. vol. 1. New York. Academic Press. 1965. pp.543-560.

DUFFIE, J.A. Solar energy thermal processes. New York. John Wiley \& Sons Inc. 1974.

FREITAS, M.A., CAFÉ FILHO, A.C. \& NASSER, L.C.B. Qualidade da água de irrigação em um núcleo rural no Distrito Federal. Fitopatologia Brasileira 26:492. 2001a (Resumo).

FREITAS, M.A., NASSER, L.C.B. \& CAFÉ FILHO, A.C. Água contaminada: fitopatógenos infestam a água. Cultivar HF 8:32-37. $2001 b$.

HIRST, J.M. Dispersal of soil microorganisms. In: Baker, K.F. \& Snyder, W.C. (Eds.) Ecology of soil borne plant pathogens. Los Angeles. Univ. California Press. 1965. pp.69-81.

IPT - Instituto de Pesquisas Tecnológicas - Coletores solares planos para líquidos: determinação do rendimento térmico. IPT/ FINEP/ INMETRO/ ABNT. Minuta 1. 1981.

JARVIS, W.R. Managing diseases in greenhouse crops. St. Paul. APS Press. 1993p.

KATAN, J., GREENBERGER, A., ALON, H. \& GRINSTEN, A. Solar heating by polyethylene mulching for the control of diseases caused by soil-borne pathogens. Phytopathology 66:683-688. 1970. LUNDE, P.J. Solar thermal engineering: space heating and hot water systems. New York. John Wiley \& Sons. 1980.

NASCIMENTO, S. R. C., MARINGONI, A.C. \& KUROZAWA, C. Comportamento de variedades de feijoeiro ao Fusarium oxysporum f. sp. phaseoli. Fitopatologia Brasileira 20:458-63. 1995.

PALZ, W. Energia solar e fontes alternativas. São Paulo. Hemus Livraria Editora Ltda. 1981.

PULMAN, G.S., DE VAY, J.E., GARBER, R.H. \& WEINHOLD, A.R. Soil solarization. Effects on Verticillium wilt of cotton and soilborne populations of Verticillium dahliae, Pythium spp., Rhizoctonia solani and Thielaviopsis basicola. Phytopathology 71:954-954. 1981.

ROTEM, J. \& PALTI, J. Irrigation and plant diseases. Annual Review of Phytopathology 7:267-288.1969.

SILVA, S., CERESINI, P.C., SOUZA, N.L. \& AGUIAR, L.F. Sensibilidade térmica micelial e esclerocial de isolados de Rhizoctonia solani GA 4 HGI. Summa Phyopathologica 22:252-256. 1996.

TANAKA, M.A.S., PASSOS, F.A., BINOTTI, C.S. \& NOVAIS, A.J. Variabilidade patogênica de isolados de Colletotrichum acutatum e C. fragariae em rizomas e pecíolos de morangueiro. Summa Phytopathologica 25:303-307. 1999.

VALARINI, P.J. Método para detecção de Xanthomonas campestris pv. phaseoli em sementes de feijão. (Tese Doutorado). Piracicaba. Escola Superior de Agricultura "Luiz de Queiroz"/USP. 1990. 